\title{
Prognostic value of estimated glomerular filtration rate and presence of proteinuria in type B aortic intramural hematoma
}

\author{
Yang Yang, Weihao Li, Mingyuan Liu, Xiaoming Zhang, Qingle Li \\ Department of Vascular Surgery, Peking University People's Hospital, Beijing, China \\ Contributions: (I) Conception and design: Y Yang, X Zhang, Q Li; (II) Administrative support: All authors; (III) Provision of study materials or \\ patients: All authors; (IV) Collection and assembly of data: Y Yang, W Li; (V) Data analysis and interpretation: All authors; (VI) Manuscript writing: \\ All authors; (VII) Final approval of manuscript: All authors. \\ Correspondence to: Xiaoming Zhang, MD. Department of Vascular Surgery, Peking University People's Hospital, Beijing 100044, China. \\ Email: rmyyxgwk@163.com; Qingle Li, MD. Department of Vascular Surgery, Peking University People’s Hospital, Beijing 100044, China. \\ Email: mailtole@126.com.
}

\begin{abstract}
Background: Although aggressive medical treatment is recommended in patients with type B aortic intramural hematoma (IMH), a variety of aortic events can occur during the later period. For early identification of these patients, the present study was aimed at evaluating the prognostic validity of estimated glomerular filtration rate (eGFR) and the presence of proteinuria in type B aortic IMH.

Methods: Data of 61 patients with type B IMH in Peking University People's Hospital from January 2008 to December 2018 were retrospectively collected. The serum creatinine level and urine protein levels were measured at admission. And eGFR were calculated by the CKD-EPI equation. Adverse aortic-related events were defined as a composite of satisfaction of criteria for surgical conversion (with or without actual surgical intervention) and death from aortic rupture.

Results: Initial eGFR was significantly different between patients with adverse aortic-related events and those without $(\mathrm{P}=0.003)$. On multivariate analysis, eGFR $<90 \mathrm{~mL} / \mathrm{min} / 1.73 \mathrm{~m}^{2}$ (OR, 8.726; 95\% CI: $1.711-$ 46.144; $\mathrm{P}=0.009)$ and ULP (OR, 17.516; 95\% CI: 3.322-92.258; P=0.001) were independent predictors of adverse aorta-related events. Furthermore, eGFR $<90 \mathrm{~mL} / \mathrm{min} / 1.73 \mathrm{~m}^{2}$ and proteinuria (+) (OR, 8.344; $\mathrm{P}=0.030)$ had significantly greater rates of aortic-related events. In addition, eGFR $<90 \mathrm{~mL} / \mathrm{min} / 1.73 \mathrm{~m}^{2}$ and proteinuria $(+)$ had incremental prognostic value (C-statistic, $0.860, \mathrm{P}=0.039)$ compared with ulcer-like projection (C-statistic, 0.815) alone.
\end{abstract}

Conclusions: Initial eGFR and presence of proteinuria were able to provide incremental prognostic information in addition to ulcer-like projection in patients with type B aortic IMH.

Keywords: Estimated glomerular filtration rate (eGFR); proteinuria; aorta; intramural hematoma (IMH)

Submitted Jul 28, 2020. Accepted for publication Dec 15, 2020.

doi: $10.21037 /$ jtd-20-2543

View this article at: http://dx.doi.org/10.21037/jtd-20-2543

\section{Introduction}

Aortic intramural hematoma (IMH) is an entity belonging to acute aortic syndrome, with the symptom of acute severe chest pain. However, its pathological features differ from the aortic dissection $(\mathrm{AD})$ or penetrating aortic ulcer (PAU). By the definition, IMH is characterized as a hematoma in the aortic media without open communication with the aortic true lumen via intimal invasion (1-5). It accounts for approximately $10-25 \%$ of acute aortic syndrome, primarily occurring in the descending aorta which is classified as type B IMH $(1,2)$. Unlike emergent/urgent surgery recommended for type A IMH $(6,7)$ aggressive medical treatment and careful clinical and imaging surveillance is indicated for type B IMH $(1,5,8)$. However, there are still variety of adverse aortic-related events manifest in the later period. Estimated glomerular filtration rate (eGFR) 
and the presence of proteinuria have been reported to independently improve the prediction of cardiovascular outcomes even in the general population $(9,10)$, and poor baseline renal function is associated with acute type A IMH (11). There is a complex pathophysiological relationship between renal impairment and aortic IMH or dissection, but there are few studies of patients with type B IMH with respect to the association between kidney function and clinical outcomes. Hence, the present study was aimed at evaluating the prognostic validity of eGFR and presence of proteinuria for predicting adverse clinical events in patients with type B IMH. We present the following article in accordance with the STROBE reporting checklist (available at http://dx.doi. org/10.21037/jtd-20-2543).

\section{Methods}

\section{Patient characteristics}

Data from January 2008 to December 2018 were retrospectively collected. The inclusion criteria were (I) patients diagnosed with type B IMH at admission to Peking University People's Hospital, Beijing, China; (II) patients presenting severe chest pain or related symptoms; and (III) patients with computed tomography angiography (CTA) results identifying a crescentic or circular thickening of over $5 \mathrm{~mm}$ of the aortic wall without contrast enhancement. Exclusion criteria were (I) the patients that underwent emergent surgery at admission; (II) patients that died without being admitted to the ward for further treatment; (III) patients or their family members that abandoned treatment; or (IV) patients that failed to follow up or could not give accurate follow up CTA results. The diagnosis was established by CTA or transesophageal echocardiography (TEE) with severe chest pain. Regional thickness of the aortic wall of $>5 \mathrm{~mm}$ in a crescent or circular shape without evidence of flow communication and limited to the aortic arch or descending aorta was defined as type B IMH.

\section{Estimated GFR and proteinuria measurement}

Serum creatinine and proteinuria were measured at admission and these data were retrospectively collected from patients' medical records. Serum creatinine was measured by the SAO method (Creatinine Assay Kit, Maccura Biotechnology, China), using an auto-analyzer (Maccura AU5800, Maccura Biotechnology, China), and proteinuria was measured by the dipstick test with a Clinitek Atlas Urine Analyzer (Siemens AG, Germany). eGFR was calculated by The Chronic Kidney Disease Epidemiology Collaboration (CKD-EPI) creatinine-based equation $(12,13)$. Because serum creatinine and proteinuria levels were included in basic metabolic panel and urinalysis (UA) which were the routine laboratory tests for patients with type B IMH, every patient had available data of serum creatinine and proteinuria levels.

\section{Treatment and surveillance}

Following the 2014 European Society of Cardiology Guidelines (ESCG 2014) on the diagnosis and treatment of aortic diseases (1), patients underwent aggressive medical therapy (blood pressure control and pain relief) with careful surveillance once the diagnosis of type B IMH was confirmed. Most patients were taking two to three antihypertensive medicines including calcium antagonists, $\beta$-blockers and angiotensin-converting enzyme inhibitors/ angiotensin receptor blockers. CTA surveillance was routinely performed 2 weeks after the initial diagnosis was confirmed. Additional CTA scanning was conducted once there was any sign of possible complications arose.

\section{Clinical follow up and CTA evaluation}

When discharged, patients were informed to schedule a clinical follow-up and CTA surveillance 3 months later at least, 6 months later, and every year thereafter for best. Moreover, a follow-up visit was recommended any time a new or repeat episode of discomfort manifested.

\section{Main outcome measures}

Adverse aortic-related events were defined by a composite of satisfaction of criteria for surgical intervention (with or without actual surgical intervention) and death from aortic rupture during hospital stay and follow-up. The surgical indications were refractory hypertension, recurrent pain, progression (hematoma expansion, aneurysm or dissection), malperfusion leading to end-organ ischemia, or rupture. In addition, the hematoma expansion was defined as the apparent increase in maximum diameter of the hematoma based on comparing the initial and last CTA.

\section{Statistical analysis}

The categorical variables are presented as numbers, 
compared using the chi-square test or Fisher's exact test as appropriate. Continuous variables are presented as the mean \pm standard deviation, compared using unpaired Student's t tests. Owing to the abnormal distribution (KolmogorovSmirnov test) of D-dimer level, platelet count, blood urea nitrogen (BUN) and eGFR, a non-parametric test (MannWhitney $\mathrm{U}$ test) was used. To determine independent risk factors for adverse aorta-related events during the follow-up period, the logistic regression was used. To evaluate the risk, the following potential variables (converting continuous variable into categorical variable) were mentioned: D-dimer $>500 \mathrm{mg} / \mathrm{L}$ (14), white blood cell (WBC) count $>10 \times 10^{9} / \mathrm{L}$ (the reference value), eGFR $<90 \mathrm{~mL} / \mathrm{min} /$ $1.73 \mathrm{~m}^{2}$ (the reference value), and ulcer-like projection (ULP). Variables with probability values $<0.05$ on univariate analysis were assessed in the multivariate analysis. For additional comparison of the prognostic values of eGFR $<90 \mathrm{~mL} / \mathrm{min} / 1.73 \mathrm{~m}^{2}$ and additional positive proteinuria, the variables eGFR $<90 \mathrm{~mL} / \mathrm{min} / 1.73 \mathrm{~m}^{2}$ and eGFR $<90 \mathrm{~mL} / \mathrm{min} / 1.73 \mathrm{~m}^{2}$ and proteinuria (+) were estimated by univariable analysis. Furthermore, these variables with ULP together respectively were estimated by multivariable analysis using logistic analysis. The C-statistic index was calculated to evaluate the prognostic value of additional eGFR or eGFR and proteinuria data to the model of ULP data alone with respect to adverse aortic-related events. The discrimination and increased discriminative value were analyzed by the Delong method. All results with $\mathrm{P}<0.05$ were considered statistically significant.

All of the aforementioned analyses were performed using SPSS Statistic, version 19.0 software (IBM Corp., Armonk, NY, USA), and MedCalc Statistical Software version 18.6 (MedCalc Software bvba, Ostend, Belgium).

\section{Ethical statement}

The study was conducted in accordance with the Declaration of Helsinki (as revised in 2013). The study was approved by the Institutional Research Ethics Board of Peking University People's Hospital (No. 2015-59) and individual consent for this retrospective analysis was waived.

\section{Results}

\section{Patient characteristics and clinical outcomes}

From January 2008 to December 2018, 73 patients were diagnosed with type B IMH at admission to Peking
University People's Hospital; 61 patients were included in the present study and 12 patients were excluded (2 patients underwent emergency surgery at admission, 1 patient died without being admitted to the ward for further treatment, 2 patients or their family members refused abandoned treatment at the emergency room, and 7 patients did not follow up or accurate follow-up CTA results could not be given) (see Figure 1).

Of the 61 type B IMH patients, 44 (72\%) were men and $17(28 \%)$ were women with a mean age of $57 \pm 9$ years. The mean clinical follow-up duration was 167.3 weeks (range, 1-481 weeks), and the mean duration between admission and the last follow-up CTA scan was 44.2 weeks (range, 1-158 weeks). After initial medical therapy, 36 patients experienced adverse aortic-related events during a hospital stay or follow-up period, and the mean time of aortic event occurrence was 4.2 weeks. Of these patients, 1 (2.8\%) died of aortic rupture, $24(66.7 \%)$ underwent endovascular or surgical repair (8 (33.4\%) for localized AD, 11 (45.8\%) for ULP progression, 2 (8.3\%) for aortic aneurysm, and $3(12.5 \%)$ for hematoma expansion), and 11 (30.6\%) had significant hematoma expansion without aortic repair (patients refused). Patients were separated in two groups by the occurrence of aortic-related events; WBC count, eGFR, and ULP from initial laboratory tests or initial CTA were significantly different between groups. More detailed clinical characteristics of both groups are listed in Table 1.

\section{Risk factors of adverse aortic-related events}

The results of univariate and multivariate analysis for risk factors of adverse aortic-related events are listed in Table 2. ULP (OR, 17.516; 95\% CI: 3.322-92.258; $\mathrm{P}=0.001)$ and eGFR $<90 \mathrm{~mL} / \mathrm{min} / 1.73 \mathrm{~m}^{2}$ (OR, 8.726; 95\% CI: 1.711-46.144; $\mathrm{P}=0.009)$ were confirmed as independent risk factors of aortic-related events.

\section{Estimated GFR levels and proteinuria}

The patients with adverse aortic-related events had significantly lower eGFR level than patients without, Furthermore, the result of univariate and multivariate analysis of eGFR $<90 \mathrm{~mL} / \mathrm{min} / 1.73 \mathrm{~m}^{2}$ (reference value) and eGFR $<90 \mathrm{~mL} / \mathrm{min} / 1.73 \mathrm{~m}^{2}$ and proteinuria (+) added ULP respectively are listed in Tables 3 and 4 respectively, and patients with eGFR $<90 \mathrm{~mL} / \mathrm{min} / 1.73 \mathrm{~m}^{2} \&$ proteinuria (+) (OR, 8.344; 95\% CI: 1.226-56.779; $\mathrm{P}=0.030)$ had greater rates of adverse aortic-related events than those 


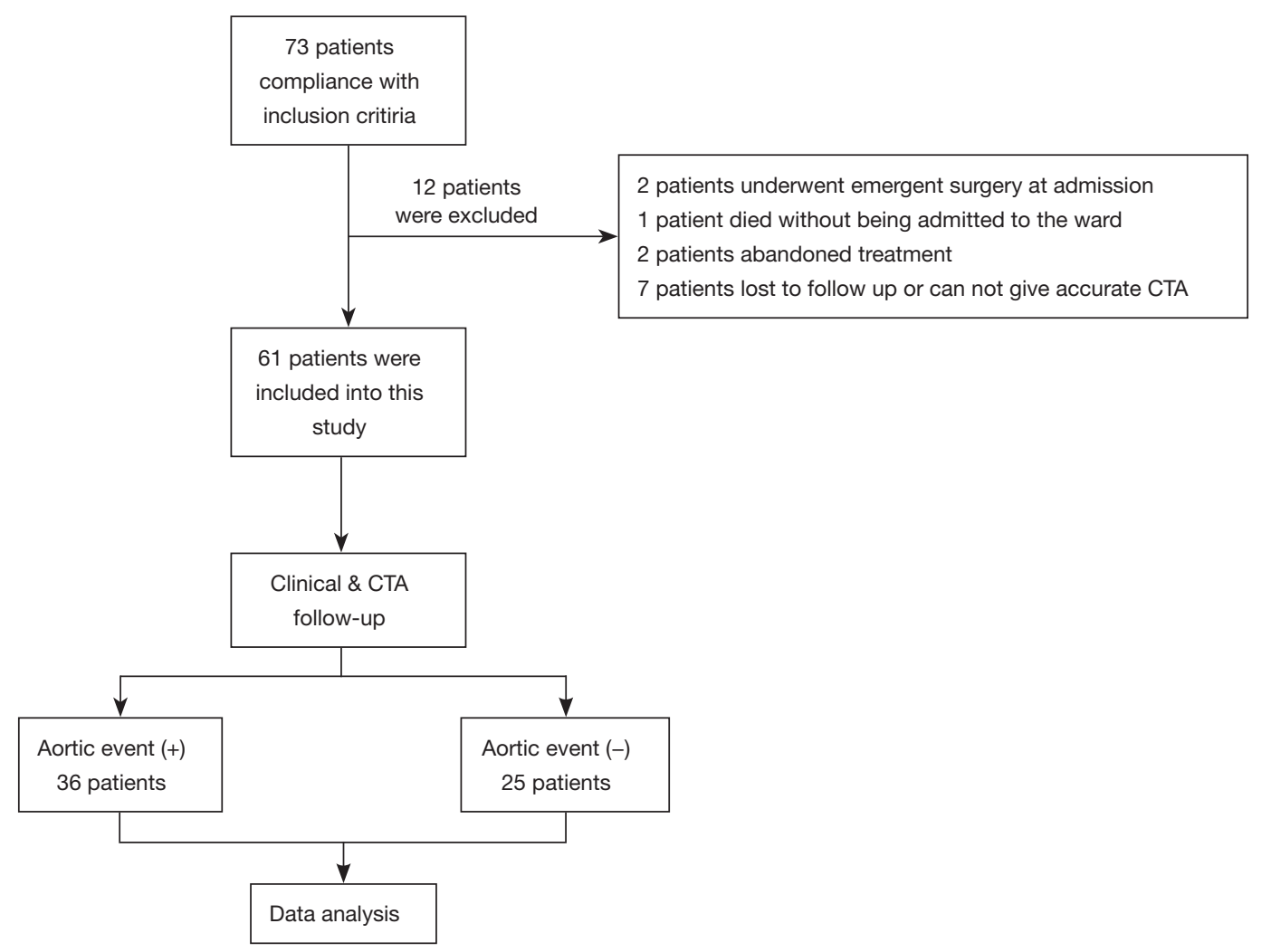

Figure 1 Patients selection of type B aortic intramural hematoma.

without decreased eGFR level or positive proteinuria. In addition, the C-statistic of these two variables over the ULP alone is listed in Table 5 . eGFR $<90 \mathrm{~mL} / \mathrm{min} / 1.73 \mathrm{~m}^{2}$ and proteinuria $(+)$ revealed a significantly increased C-statistic (C-statistic, 0.860; 95\% CI: 0.777-0.952; $\mathrm{P}=0.039$ ) which indicated the incremental prognostic value over the ULP (C-statistic, 0.815)

\section{Discussion}

The present study suggested the clinical importance of eGFR and presence of proteinuria in evaluation of patients in type B IMH. The key findings of our study were as follows: eGFR $<90 \mathrm{~mL} / \mathrm{min} / 1.73 \mathrm{~m}^{2}$ and positive proteinuria in initial laboratory test had independent association with adverse aortic-related events; and eGFR with proteinuria measurement improved prognostic value over the ULP alone.

Although eGFR $<90 \mathrm{~mL} / \mathrm{min} / 1.73 \mathrm{~m}^{2}$ or positive proteinuria alone did not have statistical significance with adverse aortic-related events in the present study, type B IMH patients with both abnormal index [eGFR
$<90 \mathrm{~mL} / \mathrm{min} / 1.73 \mathrm{~m}^{2}$ and proteinuria $(+)$ ] were at high risk of poor prognosis. Furthermore, several meta-analysis studies indicated that the combination of eGFR and proteinuria measurement had stronger value in predicting cardiovascular outcomes $(9,10)$ than did either index alone. The combination of both abnormal indexes might evaluate the value of impaired kidney function more accurately or indicate it was not a transient impairment.

Decreased eGFR and positive proteinuria are the two measurements reflecting the impaired individual's kidney function. Patients with both disorders can be considered with progression-risk of chronic kidney disease (15); in addition, most $(73.8 \%)$ patients in the present study had hypertension, the risk factor of CKD (16). Various studies and collaborative meta-analyses show that eGFR and positive proteinuria comprise an independent predictor for various cardiovascular outcomes even with mild anomaly $(9,10,15,17)$.

According to the European Society of Cardiology guidelines, the recommended immediate-treatment for type B IMH is aggressive blood pressure control and beta blockers. However, impaired kidney function can activate 
Table 1 Patient characteristics

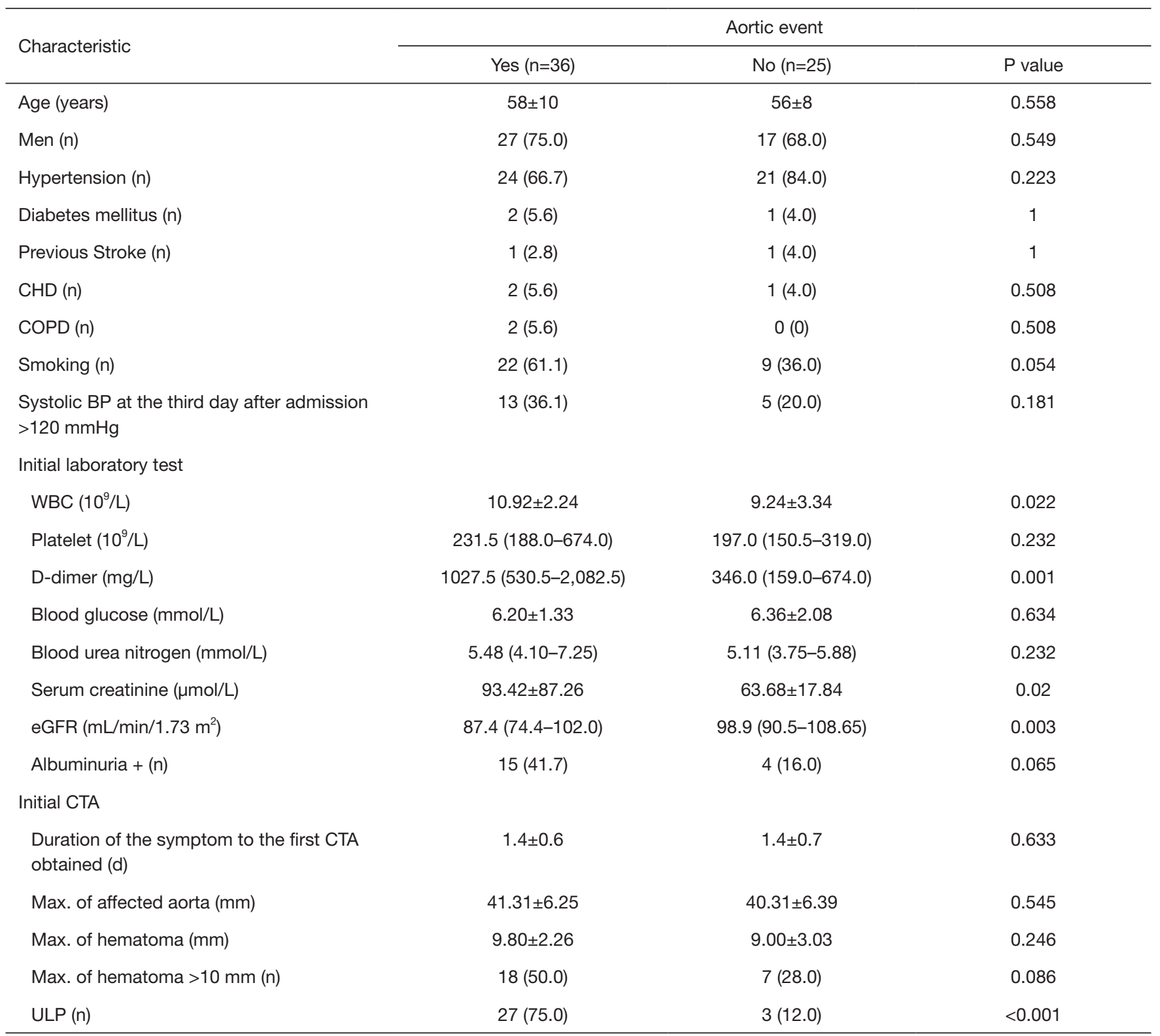

CHD, coronary heart disease; COPD, chronic obstructive pulmonary disease; BP, blood pressure; WBC, white blood cell; eGFR, estimated glomerular filtration rate; ULP, ulcer-like projection.

the renin-angiotensin system (18), concentrate plasma level of homocysteine (19) and symmetric dimethylarginine (SDMA), which is the complete inhibitor of nitric oxide synthase $(18,20)$, and eventually induce refractory hypertension. Therefore, sustained hypertension or the fluctuating blood pressure, making an already diseased aortic intima more vulnerable, is identified as a predictor of IMH complications (1-3). In addition, hypertension is associated with $\mathrm{AD}$ due to intimal tearing from high- pressure blood flow $(1,2)$. This could explain that patients with deceased eGFR and positive proteinuria were prone to adverse outcomes, especially the occurrence of $\mathrm{AD}$ or rupture.

Lately, inflammation has been proposed to be involved in arterial media damage, as a sign associated with acute aortic syndrome (21). Moreover, inflammation plays a pathological role in outcomes of aortic diseases (22). From the present study, the initial WBC counts, as the 
Table 2 Univariate and multivariate analysis of predictors of adverse aorta-related events

\begin{tabular}{|c|c|c|c|c|c|c|}
\hline Variable & \multicolumn{3}{|c|}{ Univariate analysis } & \multicolumn{3}{|c|}{ Multivariate analysis } \\
\hline ULP & 22.00 & $5.303-91.267$ & $<0.001$ & 17.516 & 3.322-92.358 & 0.001 \\
\hline WBC $>10 \times 10^{9} / L$ & 2.489 & $0.870-7.124$ & 0.089 & 1.197 & $0.262-5.461$ & 0.817 \\
\hline D-dimer $>500 \mathrm{mg} / \mathrm{L}$ & 5.333 & $1.755-16.212$ & 0.003 & 5.035 & 1.003-25.272 & 0.050 \\
\hline
\end{tabular}

*, logistic regression analysis. OR, odds ratio; Cl, confidence interval; ULP, ulcer-like projection; eGFR, estimated glomerular filtration rate.

Table 3 Univariate analysis of different kidney variables

\begin{tabular}{lccc}
\hline \multirow{2}{*}{ Variable } & \multicolumn{3}{c}{ Univariate analysis } \\
\cline { 2 - 4 } & OR & $95 \% \mathrm{Cl}$ & $\mathrm{P}$ value \\
\hline eGFR $<90 \mathrm{~mL} / \mathrm{min} / 1.73 \mathrm{~m}^{2}$ & 3.539 & $1.146-10.926$ & 0.028 \\
eGFR $<90 \mathrm{~mL} / \mathrm{min} / 1.73 \mathrm{~m}^{2} \&$ albuminuria $(+)$ & 7.318 & $1.488-35.984$ & 0.014 \\
\hline
\end{tabular}

*, logistic regression analysis. OR, odds ratio; $\mathrm{Cl}$, confidence interval; eGFR, estimated glomerular filtration rate.

Table 4 Multivariate analysis of different kidney variables with ULP

\begin{tabular}{lccc}
\hline Variable & \multicolumn{2}{c}{ Multivariate analysis } \\
\cline { 2 - 4 } Modle1 & OR & $95 \% \mathrm{Cl}$ & \\
ULP & & & \\
eGFR value $<90 \mathrm{~mL} / \mathrm{min} / 1.73 \mathrm{~m}^{2}$ & 11.294 & $2.364-53.957$ & 0.002 \\
Modle 2 & 4.014 & $0.896-17.989$ & \\
ULP & & & 0.069 \\
eGFR $<90 \mathrm{~mL} / \mathrm{min} / 1.73 \mathrm{~m}^{2} \&$ albuminuria $(+)$ & 13.760 & $2.754-65.760$ & 0.001 \\
\hline
\end{tabular}

*, logistic regression analysis. OR, odds ratio; $\mathrm{Cl}$, confidence interval; ULP, ulcer-like projection; eGFR, estimated glomerular filtration rate.

Table 5 Increment value of different kidney variables over ULP

\begin{tabular}{lcccc}
\hline Aortic-related event & C-statistic & $95 \% \mathrm{Cl}$ & $\mathrm{P}$ value \\
\hline ULP & 0.815 & $0.702-0.928$ & Reference \\
$+\mathrm{eGFR}<90 \mathrm{~mL} / \mathrm{min} / 1.73 \mathrm{~m}^{2}$ & 0.758 & $0.632-0.859$ & 0.308 \\
$+\mathrm{eGFR}<90 \mathrm{~mL} / \mathrm{min} / 1.73 \mathrm{~m}^{2} \&$ albuminuria $(+)$ & 0.860 & $0.777-0.952$ & 0.039 \\
\hline
\end{tabular}

*, C-statistic analysis. Cl, confidence interval; ULP, ulcer-like projection; eGFR, estimated glomerular filtration rate. 
robust and simple inflammatory index, were indeed different between patients with aortic-related events and those without. Decreased eGFR or even an early stage of CKD causes changes in plasma components, or even gut microbiota makes the metabolic uremic toxin trigger or sustain systemic inflammation $(18,23)$. Along with the effect of impaired kidney function, the local inflammatory reaction initially caused by hematoma formation might be amplified or sustained. Furthermore, the study of Kitai et al. suggested that the sustained elevated inflammatory biomarker-C-reactive protein level was a strong risk factor with adverse aortic-events in acute IMH (24). In addition, these inflammatory factors themselves may further impair the renal function in turn, and with the possible effect of renal artery malperfusion from the hemodynamic change in $\mathrm{IMH}$, they might lead to a vicious circle.

Furthermore, other plausible mechanisms linking impaired kidney function with adverse progression of type B IMH include oxidative stress, and abnormal calciumphosphate metabolism inducing vascular calcification and lipoprotein increasement (18). Notably, proteinuria itself is linked with endothelial dysfunction and vascular damage (25). Therefore, patients with eGFR $<90 \mathrm{~mL} / \mathrm{min} / 1.73 \mathrm{~m}^{2}$ and proteinuria (+) might accelerate the atherosclerosis change in the aorta, which is prone to ULP development and might lead to IMH expansion or aneurysm dilation (26). As mentioned, ulcer-like projection as small ulcers associated with IMH has been reported as a high-risk factor for poor outcomes by previous studies (1,27-30). In addition, from a previous study on IMH, the factors related to IMH evolution including a maximum aortic diameter of $>40 \mathrm{~mm}$, hematoma thickness of $>10 \mathrm{~mm}$ (31) and ULP (1,27-30) from imaging are all associated with instability of the aortic wall which induces aneurysmal evolution in IMH. Bolomey et al. also found that aortic diameter of $>40 \mathrm{~mm}$ and at least one ULP comprised strong predictors of aortic related events (32). However, maximum aortic diameters and hematoma thickness of $>10 \mathrm{~mm}$ have no statistical significance associated with adverse aortic related events in the present study due to limited sample size.

However, that eGFR $<90 \mathrm{~mL} / \mathrm{min} / 1.73 \mathrm{~m}^{2}$ and proteinuria (+) had an increment prognostic value over the ULP was indicated in the present study from the analysis results. Therefore, in some cases, the impaired kidney function was not just only associated with the ULP development, but it might play an independent role in poor prognosis of type B IMH. Additional studies should be undertaken to illuminate the exact mechanism of the association between impaired kidney function and adverse aortic-related events in type B IMH. Based on the results of the present study, it is suggested herein that the initial eGFR and proteinuria should be both be evaluated to predict the patients with high risk in type B IMH.

\section{Study limitations}

Several limitations existing in the present study should be acknowledged. First, this study at a single medical center of a small cohort might have data migration that affected the evaluation of the disease itself. Second, the time of followup CT scans might affect the detection of adverse aorticrelated events and ULP. Some hematoma expansion, AD, or ULP might not have been detected by earlier followup. Third, due to the retrospective nature of the present study, proteinuria was only measured by dipstick without quantitative measurement, and continuous blood creatinine or proteinuria levels were not tested in all patients or were tested on different days post-admission. The change of renal function during a hospital stay could not be further analyzed. And. Fourth, 11 patients had significant hematoma expansion and refused to undergo aortic repair, and the follow up visit was stopped after they refused further treatment. Therefore, the different levels of renal function were not assessed due to the lack of proteinuria quantitative measurement and the small cohort.

\section{Acknowledgments}

We thank LetPub (www.letpub.com) for its linguistic assistance during the preparation of this manuscript.

Funding: This study was supported by grants from the National Natural Science Foundation of China (81570426). Sponsors had no influence on the design, analysis, or publication of this study.

\section{Footnote}

Reporting Checklist: The authors have completed the STROBE reporting checklist. Available at http://dx.doi. org/10.21037/jtd-20-2543

Data Sharing Statement: Available at http://dx.doi. org/10.21037/jtd-20-2543

Conflicts of Interest: All authors have completed the ICMJE 
uniform disclosure form (available at http://dx.doi. org/10.21037/jtd-20-2543). All authors report grants from National Natural Science Foundation of China, during the conduct of the study.

Ethical Statement: The authors are accountable for all aspects of the work in ensuring that questions related to the accuracy or integrity of any part of the work are appropriately investigated and resolved. The study was conducted in accordance with the Declaration of Helsinki (as revised in 2013). The study was approved by the Institutional Research Ethics Board of Peking University People's Hospital (No. 2015-59) and individual consent for this retrospective analysis was waived.

Open Access Statement: This is an Open Access article distributed in accordance with the Creative Commons Attribution-NonCommercial-NoDerivs 4.0 International License (CC BY-NC-ND 4.0), which permits the noncommercial replication and distribution of the article with the strict proviso that no changes or edits are made and the original work is properly cited (including links to both the formal publication through the relevant DOI and the license). See: https://creativecommons.org/licenses/by-nc-nd/4.0/.

\section{References}

1. Erbel R, Aboyans V, Boileau C, et al. 2014 ESC Guidelines on the diagnosis and treatment of aortic diseases:

Document covering acute and chronic aortic diseases of the thoracic and abdominal aorta of the adult. The Task Force for the Diagnosis and Treatment of Aortic Diseases of the European Society of Cardiology (ESC). Eur Heart J 2014;35:2873-926.

2. Hiratzka LF, Bakris GL, Beckman JA, et al. 2010 ACCF/AHA/AATS/ACR/ASA/SCA/SCAI/SIR/STS/ SVM Guidelines for the diagnosis and management of patients with thoracic aortic disease. A Report of the American College of Cardiology Foundation/American Heart Association Task Force on Practice Guidelines, American Association for Thoracic Surgery, American College of Radiology, American Stroke Association, Society of Cardiovascular Anesthesiologists, Society for Cardiovascular Angiography and Interventions, Society of Interventional Radiology, Society of Thoracic Surgeons, and Society for Vascular Medicine. J Am Coll Cardiol 2010;55:e27-e129.

3. Ferrera C, Vilacosta I, Gómez-Polo JC, et al. Evolution and prognosis of intramural aortic hematoma. Insights from a midterm cohort study. Int J Cardiol 2017;249:410-3.

4. Goldberg JB, Kim JB, Sundt TM. Current understandings and approach to the management of aortic intramural hematomas. Semin Thorac Cardiovasc Surg 2014;26:123-31.

5. Norton EL, Williams DM, Kim KM, et al. Management of malperfusion syndrome in acute type A aortic intramural hematoma. Ann Cardiothorac Surg 2019;8:540-50.

6. Leshnower BG. Type A intramural hematoma: An unstable, unpredictable enigma. J Thorac Cardiovasc Surg 2018;155:910-1.

7. Hata M, Hata H, Sezai A, et al. Optimal treatment strategy for type A acute aortic dissection with intramural hematoma. J Thorac Cardiovasc Surg 2014;147:307-11.

8. Evangelista A, Czerny M, Nienaber C, et al. Interdisciplinary expert consensus on management of type $\mathrm{B}$ intramural haematoma and penetrating aortic ulcer. Eur J Cardiothorac Surg 2015;47:209-17.

9. Matsushita K, Coresh J, Sang Y, et al. CKD Prognosis Consortium. Estimated glomerular filtration rate and albuminuria for prediction of cardiovascular outcomes: a collaborative meta-analysis of individual participant data. Lancet Diabetes Endocrinol. 2015;3:514-25.

10. Ballew SH, Matsushita K. Cardiovascular Risk Prediction in CKD. Semin Nephrol 2018;38:208-16.

11. Sandhu HK, Tanaka A, Charlton-Ouw KM, et al. Outcomes and management of type A intramural hematoma. Ann Cardiothorac Surg 2016;5:317-27.

12. Matsushita K, Mahmoodi BK, Woodward M, et al. Chronic Kidney Disease Prognosis Consortium. Comparison of risk prediction using the CKD-EPI equation and the MDRD study equation for estimated glomerular filtration rate. JAMA 2012;307:1941-51.

13. Liao Y, Liao W, Liu J, et al. Assessment of the CKDEPI equation to estimate glomerular filtration rate in adults from a Chinese CKD population. J Int Med Res 2011;39:2273-80.

14. Watanabe H, Horita N, Shibata $Y$, et al. Diagnostic test accuracy of D-dimer for acute aortic syndrome: systematic review and meta-analysis of 22 studies with 5000 subjects. Sci Rep 2016;6:26893.

15. Levin A, Stevens PE, Bilous RW, et al. Kidney Disease: Improving Global Outcomes (KDIGO) CKD Work Group. KDIGO Clinical Practice Guideline for the Evaluation and Management of Chronic Kidney Disease. Kidney Int Suppl 2013;3:1-150.

16. Inker LA, Okparavero A, Tighiouart H, et al. Midlife 
Blood Pressure and Late-Life GFR and Albuminuria: An Elderly General Population Cohort. Am J Kidney Dis 2015;66:240-8.

17. Chobanian AV, Bakris GL, Black HR, et al. National Heart, Lung, and Blood Institute Joint National Committee on Prevention, Detection, Evaluation, and Treatment of High Blood Pressure; National High Blood Pressure Education Program Coordinating Committee. The Seventh Report of the Joint National Committee on Prevention, Detection, Evaluation, and Treatment of High Blood Pressure: the JNC 7 report. JAMA 2003;289:2560-72.

18. Schiffrin EL, Lipman ML, Mann JF. Chronic kidney disease: effects on the cardiovascular system. Circulation 2007;116:85-97.

19. Levi A, Cohen E, Levi M, et al. Elevated serum homocysteine is a predictor of accelerated decline in renal function and chronic kidney disease: A historical prospective study. Eur J Intern Med 2014;25:951-5.

20. Emrich IE, Zawada AM, Martens-Lobenhoffer J, et al. Symmetric dimethylarginine (SDMA) outperforms asymmetric dimethylarginine (ADMA) and other methylarginines as predictor of renal and cardiovascular outcome in non-dialysis chronic kidney disease. Clin Res Cardiol 2018;107:201-13.

21. Kuehl H, Eggebrecht H, Boes T, et al. Detection of inflammation in patients with acute aortic syndrome: comparison of FDG-PET/CT imaging and serological markers of inflammation. Heart 2008;94:1472-7.

22. Sakakura K, Kubo N, Ako J, et al. Peak C-reactive protein level predicts long-term outcomes in type $\mathrm{B}$ acute aortic dissection. Hypertension 2010;55:422-9.

23. Meijers B, Jouret F, Evenepoel P. Linking gut microbiota to cardiovascular disease and hypertension: Lessons from

Cite this article as: Yang Y, Li W, Liu M, Zhang X, Li Q. Prognostic value of estimated glomerular filtration rate and presence of proteinuria in type B aortic intramural hematoma. J Thorac Dis 2021;13(2):946-954. doi: 10.21037/jtd-20-2543 chronic kidney disease. Pharmacol Res 2018;133:101-7.

24. Kitai T, Kaji S, Kim K, et al. Prognostic value of sustained elevated C-reactive protein levels in patients with acute aortic intramural hematoma. J Thorac Cardiovasc Surg 2014;147:326-31.

25. El Nahas M. Cardio-Kidney-Damage: a unifying concept. Kidney Int 2010;78:14-8.

26. Sueyoshi E, Onizuka H, Nagayama H, et al. Clinical importance of minimal enhancement of type $\mathrm{B}$ intramural hematoma of the aorta on computed tomography imaging. J Vasc Surg 2017;65:30-9.

27. Sebastià C, Evangelista A, Quiroga S, et al. Predictive value of small ulcers in the evolution of acute type $B$ intramural hematoma. Eur J Radiol 2012;81:1569-74.

28. Kitai T, Kaji S, Yamamuro A, et al. Impact of new development of ulcer-like projection on clinical outcomes in patients with type $\mathrm{B}$ aortic dissection with closed and thrombosed false lumen. Circulation 2010;122:S74-80.

29. Buckley O, Rybicki FJ, Gerson DS, et al. Imaging features of intramural hematoma of the aorta. Int J Cardiovasc Imaging 2010;26:65-76.

30. Liu YJ, Zhang QY, Du ZK, et al. Long-term follow-up and clinical implications in Chinese patients with aortic intramural hematomas. Int J Cardiol 2018;270:268-272.

31. Jiang D, Kuang F, Lai Y, et al. Certain aortic geometries and hemodynamics are associated with FID development and impact the evolution of uncomplicated type B intramural hematoma during the acute phase. J Card Surg 2019;34:337-47.

32. Bolomey S, Blanchard A, Barral PA, et al. Is the Natural Anatomical Evolution of Type B Intramural Hematomas Reliable to Identify the Patients at Risk of Aneurysmal Progression? Ann Vasc Surg 2020;64:62-70. 